\title{
Non-Compete Covenants, Litigation and Garden Leaves ${ }^{\text {th }}$
}

\author{
Alcino Azevedo ${ }^{\mathrm{a}}$, Paulo J. Pereira ${ }^{\mathrm{b}, *}$, Artur Rodrigues ${ }^{\mathrm{c}}$ \\ ${ }^{a}$ Aston Business School, Aston University, Aston Triangle, B4 7ET Birmingham, UK. \\ E-mail address: a.azevedo@aston.ac.uk. \\ ${ }^{b}$ CEF.UP and Faculdade de Economia, Universidade do Porto, Rua Dr. Roberto Frias, \\ 4200-464 Porto-Portugal. E-mail address: pjpereira@fep.up.pt. \\ ${ }^{c}$ NIPE and School of Economics and Management, University of Minho, Campus de \\ Gualtar,4710-057Braga-Portugal.E-mail address: artur.rodrigues@eeg.uminho.pt
}

\begin{abstract}
We develop a dynamic model which assesses non-compete covenants (NCC) and garden leaves (GL) and examine the effect of the uncertainty, embargo period and severance payment on the manager's behavior and the reimbursement amount that is due to the firm if there is a violation of the NCC. We find that if the firm wants to deter the manager from leaving, the NCC is more effective than the GL when the industry uncertainty is low, or the embargo period is long, or the salary of the manager now or when working outside the industry is low, or the salary of the manager when working for the competitor or the gain of the competitor due to the arrival of the manager is high. Otherwise, the GL is more advisable. However, contrary to the usual higher tolerance about GL, our results show that, overall, NCC are less harmful than GL.
\end{abstract}

Keywords: Non-Compete Covenant, Garden Leave, Litigation, Real Options, Uncertainty.

\footnotetext{
This work was carried out within the funding with COMPETE reference n. POCI01-0145-FEDER-006683 (Artur Rodrigues) and POCI-01-0145-FEDER-006890 (Paulo J. Pereira), FCT/MEC's (Fundação para a Ciência e a Tecnologia, I.P.), and ERDF through the Operational Programme on Competitiveness and Internationalization - COMPETE 2020 under the PT2020 Partnership Agreement.

* Corresponding author.
} 


\section{Introduction}

"The former employee who departs with confidential business information is the most exasperating of all competitors". Human resources are assets over which firms cannot exercise ownership (Garmaise, 2011). The value created by employees with technical know-how and key knowledge of markets and costumers grew enormously. Yet, employees are leaving more frequently their jobs to work for competitors or to start their own businesses. Thus, from the employer's point of view, non-competition covenants (NCC) in employment agreements often do make sense.

A NCC is a contract which preserves firms' private business information from their former employees whose departure may lead to unfair competition. It became increasingly popular to guard against the risk of losing confidential information to competitors after the termination of the employment. Confidential information means knowledge not publicly known in a given industry which confers a competitive advantage over the firms which do not own it. ${ }^{2}$

A typical NCC states that after the termination of the employment for any reason, the employee will not work in the same or similar business activities, for herself or for anyone else, within a designated geographical area during a given time period (Hutter, 1981). NCC are popular for long time (Blake, 1960; Starr et al., 2017) and, for instance in the US, are used not only in the information technology (IT) industry but also in other industries such as insurance, banking and law, and even in less-skilled knowledge industries such as hairdressing (Kräkel and Sliwka, 2009). ${ }^{3,4}$ There is also US data suggesting that about half of the technical professionals are asked to sign a NCC (Marx, 2011). The need of a NCC is however partly a function of the probability of opportunistic behaviors in the employment relationship. The greater the probability of particular types of opportunism, the greater is the need of a NCC (Barney et al., 1994).

\footnotetext{
${ }^{1}$ Belmont Laboratories, Inc. v. FTC, 103 F.2d 538, 542 (3d Cir. 1939).

${ }^{2}$ For instance, trade secrets, goodwill embedded in customer lists and other intangible assets.

${ }^{3}$ See New York Times: http://www.nytimes.com/2014/06/09/business/noncompeteclauses-increasingly-pop-up-in-array-of-jobs.html.

${ }^{4}$ The first known decision involving an employment covenant was in 1414, now known as the Dyer's Case, where a master tried to extend the period of subservience of an apprentice, restricting his rights to work as a craftsman. For a further discussion on the history of the NCC see: Blake (1960) and Bryenton (1964).
} 
A NCC has value for the employers because, during the embargo period, it protects sensible business information, but destroys value for the employees because, over the embargo period, they are not allowed to work for the competitors of their former employer, where their knowledge and expertise are more appreciated and they could earn a higher salary. In the limit, employees may choose not to join a firm due to the restrictive nature of the NCC, preventing the organization from gaining an initial competitive advantage. Thus, a fair negotiation of a NCC should include a severance payment which (at least) offsets the opportunity cost of the manager related with the termination of the employment and the constrains of the covenant. It has been also argued that the advantages of NCC to the public are the protection of proprietary interests, facilitation of investments in $R \& D$ and encouragement of human capital (personnel) development, whereas the disadvantages are the potential of limiting competition, impeding the dissemination of information and retarding the economic mobility of employees (Anenson, 2005).

For instance, Gilson (1999) and Hyde (2003) suggest that one of the main reasons for the success of the high technology industrial district in Silicon Valley and the failure of the one in Massachusetts' Route 128 was the differential enforcement of covenants not to compete. The different legal environments led to higher employee turnover and, therefore, more firms in California (see also Buente, 2012; Bishara and Orozco, 2012). Furthermore, Conti (2014) investigates the effect of NCC on the type of R\&D activity firms undertake, using a dataset on the US patent applications, and concludes that these contracts reduce the outbound mobility and knowledge leakages to competitors, making the high-risk $R \& D$ projects relatively more valuable than the low-risk ones and, therefore, inducing firms to choose riskier projects. Kobeissi et al. (2010) study how state regulation of NCC agreements affect the payment methods, premiums and abnormal returns on M\&As.

Managers often breach NCC agreements arguing that they were illegal and this behavior is considered admissible by courts. A typical litigation concerns cases where one business hires the employee of the other in apparent violation of a NCC (Anenson, 2005). A well-known case is that which involved Kai-Fu Lee, a renowned well-connected computer scientist and former worker of Microsoft in China, who was later appointed president of Google in China and, shortly after, Microsoft revealed that he was subject to a NCC. Microsoft went to court in Seattle, Washington, which issued a restraining order forbidding temporarily Kai-Fu Lee to work on projects for 
Google similar to those he performed for Microsoft. ${ }^{5,6}$ In the IT industry, the fear of workers being poached is such that some large firms, including Google, Apple, Yahoo and Genentech, have informally agreed not to hire managers from firms they view as partners (Helfdt, 2009a,b). ${ }^{7}$

Courts tend to see NCC very unfavorably, particularly in the US and the UK (Callahan, 1985). For instance, some US states, such as California, Alabama and Alaska, forbid the use of these contracts, whereas Texas and Michigan restrict significantly their use (Den Hertog, 2003). Also, in the UK in the 1980's, courts' decisions on NCC were so frequently unfavorable that this contract was gradually replaced by the so-called garden leave (GL). A GL has a similar restriction as the NCC regarding working for a competitor, and can prevent the employee from working at all, but during the embargo period the employee is paid full salary, including benefits, by her (soon to be) ex-employer. ${ }^{8}$ Recent evidence shows that the UK courts are still more supportive of GL than of NCC (Klein and Pappas, 2009).

There is however an interesting case with PepsiCo where, despite the absence of a NCC agreement, the court imposed an injunction to one of its former employees that prevented him from working for a competitor, advocating that due to the nature of his work at PepsiCo it would be impossible for him not to take advantage from confidential information.

The empirical literature on NCC is yet limited and focuses mainly on the US labor market and, in particular, on three occupations: physicians (Lavetti et al., 2014), engineers (Marx, 2011; Marx et al., 2015) and CEOs (Garmaise, 2011; Bishara and Starr, 2016; Schwab and Thomas, 2006). For instance, Marx (2011) suggests that about half of the technical professionals in the US are asked to sign a NCC. Additionally, he concludes that ex-employees that were tied to a NCC are more likely to take career detours and that firms manage strategically the timing of the NCC agreement, waiting for

\footnotetext{
${ }^{5}$ In 2000, Kai-Fu Lee had signed an agreement providing that, for a period of one year after leaving Microsoft, he would not "accept employment or engage in activities competitive with products, services, or projects... on which [he] worked or about which [he] learned confidential or proprietary information or trade secrets while employed at Microsoft."

${ }^{6}$ For further details see also: Bakerand Hosteller LLP Executive Alert, September 2005.

${ }^{7}$ For further information see: http://www.nytimes.com/2009/06/03/technology/companies/03trust.html? and http://www.nytimes.com/2009/06/04/technology/companies/04trust.html?

${ }^{8}$ The employee is to some extent on a "paid vacation".
} 
the employee's bargaining power to weaken. Marx et al. (2015) conclude that about 70.2 percent of firms use NCC with their top executives, and their enforceability reduces significantly the executive mobility. Schwab and Thomas (2006) find that about two-thirds of the CEO employment contracts have a NCC, and that the correlation between the length of the embargo period and the severance payment awarded to a departing CEO is weak. More recently, Starr et al. (2017) show that in 2014 about 20 percent of the labor force have employment contracts with a NCC, and almost 40 percent of the labor force have signed at least once a NCC agreement, being these agreements more popular in high-skill and high-paying jobs.

A manager can sign a NCC when hired, after being hired or when leaving the firm. But if a NCC is to be signed, it should be studied very carefully in order to be enforceable in case of litigation. We note that the "unnecessarily long time span of the agreement" is the main reason why NCC are very often considered illegal in the US. If there is litigation, courts inquire whether the contract is socially and economically "reasonable" (Gaby Hardwicke Solicitors, 2011). Because there is not yet a well-established formal theoretical framework to assess the firm-manager competing interests related to NCC. Hence, courts do not have a formal theoretical guide to follow in order to judge the legitimacy of NCC and determine the effect on firm's value of a violation of this contract, which may lead to "ad-hoc" decisions, increases litigation uncertainty and enhances both inefficiencies in the labor market and distortions in the employment relationships (Bitè, 2011).

We develop a theoretical valuation model for a NCC. Although quite distinct in multiple aspects, this work intersects with those of the literature on executive compensation, which examine the relationship between market conditions and executive turnover, or the association between stock option policy and managers retention, or the role of the severance payment in the optimal corporate governance structure (e.g., Peters and Wagner, 2014; Almazan and Suarez, 2003; Dahiya and Yermack, 2008; Edmans and Gabaix, 2009). It also relates to the labor law literature devoted to NCC and GL in employment agreements (e.g., Callahan, 1985; Anenson, 2005; Bishara and Orozco, 2012; Mack, 2015; Horvitz, 2016), and the labor economics literature, for instance with research on the relation between the use of NCC and the labor market mobility, or the association between the use of NCC and the innovation pace (e.g., Den Hertog, 2003; Garmaise, 2011; Kräkel and Sliwka, 2009; Marx, 2011; Conti, 2014; Tang et al., 2016).

Our paper contributes to the finance literature in several ways. Firstly, it 
presents the first theoretical model that assesses the firm-manager competing economic interests associated with the usage of NCC in employment agreements considering uncertainty. Secondly, our model quantifies the effect of a violation of the NCC embargo period on the firm's value and the manager's wealth, which turns it also useful for courts to set the fair reimbursement amount that is due to the firm in case of litigation. Thirdly, we extend our model to the valuation of a GL and provide a comparative analysis which enables the characterization of the market conditions in which the NCC might be preferred to the GL, and vice versa. We show that both the firm and the manager behavior is largely influenced by the optionality nature of the NCC.

This work provides a formal theoretical guide for the negotiation of NCC and GL in employment contracts. It may have therefore a positive effect on the popularity of these contracts in the future, by preventing litigation or reducing litigation uncertainty, namely that which is related to the fair reimbursement amount that is due to the firm when there is a violation of the NCC. It can also help policy makers in the development of more efficient labor laws and regulations involving NCC and GL.

The rest of the paper is organized as follows. Section 2 presents our model for the valuation of the NCC and provides a sensitivity analysis. Section 3 studies the scenario where the manager violates the NCC and shows our analytical solution for the reimbursement amount that is due to the firm. Section 4 presents our model for the valuation of the GL and provides a sensitivity analysis. Section 5 studies the wealth effects. Section 6 concludes the paper.

\section{The Model}

Consider a market with two active firms, $i$ and $j$, with profits $x K_{i}$ and $x K_{j}$, respectively, which depend on a stochastic factor $(x)$ and the firm's capital stock, $K_{i}$ and $K_{j}$. Assume that $x$ evolves over time according to a geometric Brownian motion (GBM):

$$
d x=\alpha x d t+\sigma x d z
$$

where $\alpha, \sigma$, and $d z$ are, respectively, the drift under the risk-neutral measure, the volatility, and the increment of a Wiener process. Without loss of generality we normalize the capital stocks and assume that the two firms are symmetric $\left(K_{i}=K_{j}=1\right)$. 
Assume also that a manager is currently working for firm $i$, earning a salary that is a percentage $\left(w_{i}\right)$ of $x$. Furthermore, suppose that firm $i$ is afraid that the manager may leave the employment in the future to work for a competitor (firm $j$ ). This is a problem for firm $i$ because the manager holds valuable business information which, if it is shared with firm $j$, will lead to an immediate profit loss to firm $i$ (a gain to firm $j$ ). Let us assume that this loss (gain) is given by a factor $\theta \in(0,1)$ which represents a percentage of $x .^{9}$

To prevent the above profit loss, firm $i$ negotiates with the manager a NCC that forbids her from working for firm $j$ over a given embargo period $(T)$ after she leaves the employment. The NCC has value for firm $i$ because it protects valuable business information from a competitor over the embargo period, but destroys value for the manager because it deters her from working in the industry (firm $j$ ) immediately after leaving firm $i$, which reduces the value of her "option to leave" firm $i$. Thus, the manager should only accept the NCC if she receives a severance payment which (at least) offsets the devaluation of the option to leave firm $i$.

Suppose now that both the firm $i$ and the manager agree with a NCC and the latter leaves the employment at a given time $\left(t_{L}\right)$. Because the manager cannot work immediately for firm $j$, the profit loss $(\theta x)$ for firm $i$ caused by the termination of the employment is deferred to the end of the embargo period. Finally, assume that the manager's salary outside the industry is given by $w_{o}$ and is independent of $x$.

The maturity of the NCC is finite, therefore, over the embargo period, the manager holds a forward-start option (FSO) that gives her the right to reenter the industry after the embargo period. Let us define $t_{C}=t_{L}+T$, where $t_{C}$ is the time at which the NCC expires and $t_{L}$ is the time at which the manager leaves firm $i$, and $t_{R}$ as the time at which the manager reenters the industry. If at $t_{C}$ it is optimal for the manager to reenter the industry, then $t_{C}=t_{R}$, otherwise $t_{C}<t_{R}$. Finally, assume that the manager reenters the industry at $t_{R}$ with a salary $w_{j}(1+\theta) x$, where $w_{j}$ is a percentage of $x$.

This timing optimization problem comprises three stages, which we illustrate in Figure 1. Note that both the optimal time to exercise the option to leave firm $i$ and the value of the FSO depend on the future evolution of $x$, which is not known ex ante. To solve this optimization problem we follow a

\footnotetext{
${ }^{9}$ Without loss of generality, we assume that firm $i$ 's profit loss corresponds to firm $j$ 's profits gain.
} 


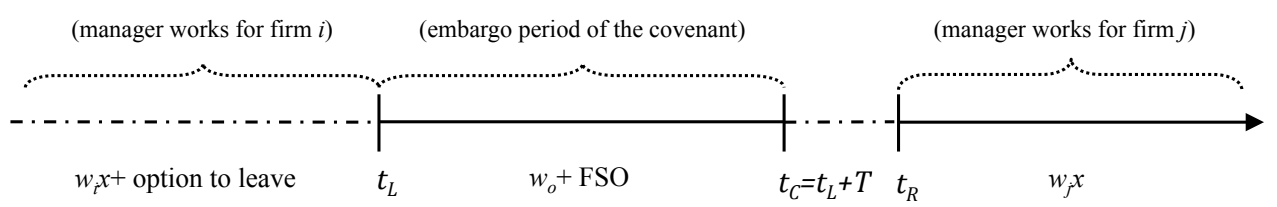

Figure 1: Time line. At $t_{L}$ the manager leaves firm $i$ and starts working outside the industry, during the embargo period of the NCC. At $t_{C}$ the embargo period ends. At $t_{R}$ the manager reenters the industry, working for firm $j$. Up to $t_{L}$ is the Stage 1 , where the manager works for firm $i$. Between $t_{L}$ and $t_{R}$ is the Stage 2 , where the manager works outside the industry. After $t_{R}$ is the Stage 3, where the manager works for firm $j$. For simplicity of the illustration we set $t_{R}>t_{C}$, but $t_{R}=t_{C}$ is also possible if, at $t_{C}$, it is optimal for the manager to reenter the industry. For simplicity, in our analytical derivations we set $t_{L}=0$, thus $t_{C}=T$.

standard backwards-induction procedure. Specifically, we start by the timing optimization of the last stage and work then backwards until the timing optimization of the first stage.

Thus, while in Stage 2, the manager holds the option to reenter the industry $(R(x))$ which, according to a contingent-claim analysis, must satisfy the following ordinary differential equation:

$$
\frac{1}{2} \sigma^{2} x^{2} R_{x x}(x)+\alpha x R_{x}(x)-r R(x)=0
$$

whose general solution is:

$$
R(x)=A_{1} x^{\beta_{1}}+A_{2} x^{\beta_{2}}
$$

where $A_{1}$ and $A_{2}$ are arbitrary constants to be determined and $\beta_{1}$ and $\beta_{2}$ are, respectively, the positive and the negative roots of the following characteristic quadratic equation: $0.5 \sigma^{2} \beta(\beta-1)+\alpha \beta-r=0$, given by:

$$
\begin{aligned}
& \beta_{1}=\frac{1}{2}-\frac{\alpha}{\sigma^{2}}+\sqrt{\left(\frac{\alpha}{\sigma^{2}}-\frac{1}{2}\right)^{2}+\frac{2 r}{\sigma^{2}}}>1 \\
& \beta_{2}=\frac{1}{2}-\frac{\alpha}{\sigma^{2}}-\sqrt{\left(\frac{\alpha}{\sigma^{2}}-\frac{1}{2}\right)^{2}+\frac{2 r}{\sigma^{2}}}<0
\end{aligned}
$$


The option is worthless for $x=0$, therefore we must set $A_{2}=0$. The optimal time for the manager to reenter the industry $\left(t_{R}\right)$ is defined as:

$$
t_{R}=\inf \left\{t \geqslant t_{C}: x(t) \geqslant x_{R}\right\}
$$

where $x_{R}$ is the optimal threshold to reenter the industry. For simplicity of notation, hereafter, we set $t_{L}=0$, thus $t_{C}=T$.

The constant $A_{1}$ and the trigger $x_{R}$ are determined using the so-called value-matching and smooth-pasting conditions, given by Equations (7) and (8), respectively:

$$
\begin{aligned}
A_{1} x_{R}^{\beta_{1}} & =w_{j}(1+\theta) \frac{x_{R}}{r-\alpha}-\frac{w_{o}}{r} \\
\beta_{1} A_{1} x_{R}^{\beta_{1}-1} & =w_{j}(1+\theta) \frac{1}{r-\alpha}
\end{aligned}
$$

The economic interpretation for Equation (7) is as follows: the term in the left-hand side represents the value of the option to reenter the industry. This option is exercised at the first moment its value equals that of the terms in the right-hand side, where the first represents the manager's gain from reentering the industry, which comprises a percentage $w_{j}$ of both the market profit and the firm $j$ 's profit gain associated with the manager's reentry in the industry, and the second represents the manager's salary outside the industry (an opportunity cost if the manager reenters the industry).

Using Equations (7) and (8) we obtain both the value of the option and the threshold to reenter the industry, respectively:

$$
\begin{gathered}
R(x)=\left\{\begin{array}{cc}
\left(w_{j}(1+\theta) \frac{x_{R}}{r-\alpha}-\frac{w_{o}}{r}\right)\left(\frac{x}{x_{R}}\right)^{\beta_{1}} & \text { for } x<x_{R} \\
w_{j}(1+\theta) \frac{x}{r-\alpha}-\frac{w_{o}}{r} & \text { for } x \geqslant x_{R}
\end{array}\right. \\
x_{R}=\frac{\beta_{1}}{\beta_{1}-1} \frac{r-\alpha}{w_{j}(1+\theta)} \frac{w_{o}}{r}
\end{gathered}
$$

We turn now our attention to the beginning of Stage 2 where, due to the embargo period, the manager holds a FSO to reenter the industry whose 
value is given by: ${ }^{10}$

$$
\begin{aligned}
F(x, T)= & w_{j}(1+\theta) \frac{x}{r-\alpha} e^{-(r-\alpha) T} N\left(d_{1}(x, T)\right)-\frac{w_{o}}{r} e^{-r T} N\left(d_{2}(x, T)\right) \\
& +\left(w_{j}(1+\theta) \frac{x_{R}}{r-\alpha}-\frac{w_{o}}{r}\right)\left(\frac{x}{x_{R}}\right)^{\beta_{1}} N\left(-d_{3}(x, T)\right)
\end{aligned}
$$

where $N($.$) is the cumulative normal integral, and$

$$
\begin{aligned}
& d_{1}(x, T)=\frac{\ln \left(\frac{x}{x_{R}}\right)+\left(\alpha+\frac{1}{2} \sigma^{2}\right) T}{\sigma \sqrt{T}} \\
& d_{2}(x, T)=d_{1}(x, T)-\sigma \sqrt{T} \\
& d_{3}(x, T)=d_{1}(x, T)+\left(\beta_{1}-1\right) \sigma \sqrt{T}
\end{aligned}
$$

In the right-hand side of Equation (11), the first two terms represents the value of the FSO if $x_{R}$ is reached before or at $T$ (this is equivalent to the value of an European option on a dividend paying stock with maturity $T$ that is exercised at $T$ if $x(T) \geqslant x_{R}$ ), and the last term represents the value of the FSO if, at $T, x_{R}$ has not yet been reached (this is equivalent to the value of an American option which exists if, at $T, x_{R}$ has not yet been reached).

Now let us focus on the optimization problem at Stage 1, where the manager works for firm $i$ with a salary $w_{i} x$ and holds the option to leave the employment, $L(x, T)$. The value-matching and smooth-pasting conditions for this case are:

$$
\begin{aligned}
B_{2} x_{L}^{\beta_{2}} & =F\left(x_{L}, T\right)+C+\frac{w_{o}}{r}-w_{i} \frac{x_{L}}{r-\alpha} \\
\beta_{2} B_{2} x_{L}^{\beta_{2}-1} & =F_{x}\left(x_{L}, T\right)-w_{i} \frac{1}{r-\alpha}
\end{aligned}
$$

where $x_{L}$ is the manager's optimal threshold to leave firm $i$ and $C$ is the severance payment associated with the NCC.

The economic interpretation for Equation (15) is as follows: the term in the left-hand side represents the value of the option to leave firm $i$. Note that the payoff of the option to leave firm $i$ resembles that of a put option. ${ }^{11}$ This

\footnotetext{
${ }^{10}$ The analytical derivation of the FSO value is provided in the Appendix A.

${ }^{11}$ Note that $L(x, T)$ is the solution for an ordinary differential equation similar to that represented by Equation (2), with the following general solution: $L(x, T)=B_{1} x^{\beta_{1}}+B_{2} x^{\beta_{2}}$. Hence, using standard arguments from the real options framework, for a put option we conclude that $B_{1}=0$.
} 
option should be exercised at the first moment its value equals that which is represented by the terms in the right-hand side, where the first is the value of the FSO, the second is a severance payment, the third is the manager's salary while working outside the industry, and the fourth is an opportunity cost for leaving firm $i$.

The manager holds the option to leave which is exercised at the threshold $x_{L}$, considering the terms of the NCC $(C$ and $T)$. Following standard real options procedures we obtain the expression below for the value of the option to leave firm $i$ :

$$
L(x, T)= \begin{cases}C+\frac{w_{o}}{r}+F(x, T)-w_{i} \frac{x}{r-\alpha} & \text { for } x<x_{L} \\ \left(C+\frac{w_{o}}{r}+F\left(x_{L}, T\right)-w_{i} \frac{x_{L}}{r-\alpha}\right)\left(\frac{x}{x_{L}}\right)^{\beta_{2}} & \text { for } x \geqslant x_{L}\end{cases}
$$

and the optimal threshold $\left(x_{L}\right)$ for the manager to leave firm $i$, which is determined numerically using:

$$
\beta_{2}\left(C+\frac{w_{o}}{r}+F\left(x_{L}, T\right)-w_{i} \frac{x_{L}}{r-\alpha}\right)-F_{x}\left(x_{L}, T\right) x_{L}+w_{i} \frac{x_{L}}{r-\alpha}=0
$$

\subsection{Results}

In this section we present our results and a sensitivity analysis. Specifically, Figure 2 shows the effect of $C$ on $x_{L}$ for a given set of $T$ values, and reveals that $x_{L}$ increases with $C$ and decreases with $T$. Thus, a higher severance payment motivates the manager to leave the employment earlier, whereas a longer embargo period persuades the manager to leave the employment later. Our results also show that the sensitivity of $x_{L}$ to $T$ increases with $C$. These findings partially corroborate Schwab and Thomas (2006) results, showing that for later departures the relationship between the embargo period and the severance payment is weaker.

Figure 3 shows the effect on $x_{L}$ of our model parameters, for a given set of $C$ and $T$ values. Although with slightly different sensitivities, we find that $x_{L}$ decreases with $T$ and increases with $C$ for all the model parameters. Thus, a longer embargo period delays and a higher severance payment accelerates the termination of the employment. As suggested by Marx (2011), managers tied with NCC are more likely to take career detours.

Additionally, Figures 3(a) and 3(b) show that $x_{L}$ decreases significantly with $\sigma$, therefore, the manager leaves the employment later as the uncertainty 


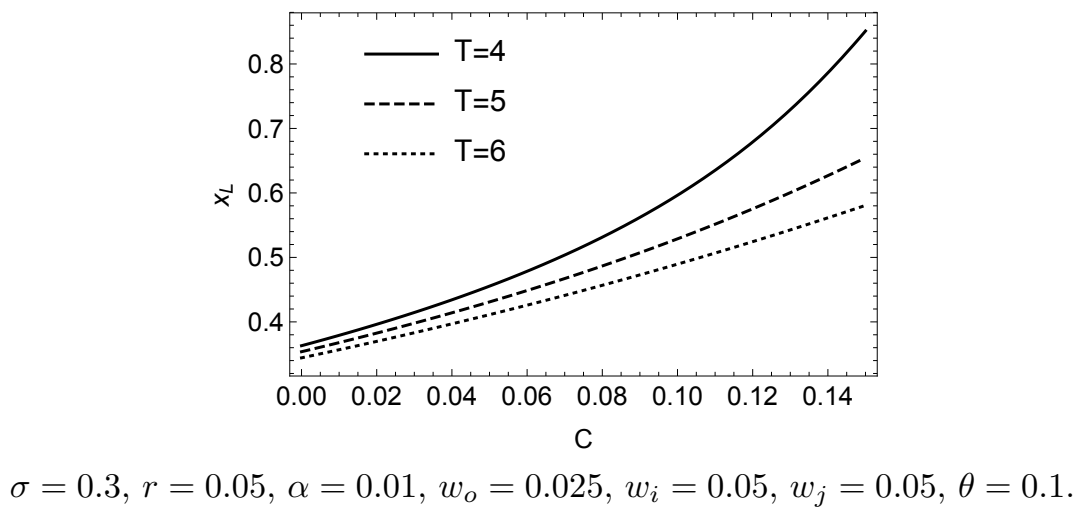

Figure 2: A sensitivity analysis for the effect of the severance payment $(C)$ and the embargo period of a non-compete covenant (NCC) on the optimal threshold to leave firm $i\left(x_{L}\right)$.

increases. We also conclude that the sensitivity of $x_{L}$ to changes in $T$ and $C$ decreases with the industry uncertainty. Figures $3(\mathrm{c})$ and $3(\mathrm{~d})$ show that $x_{L}$ increases with $w_{o}$, Figures $3(\mathrm{e})$ and $3(\mathrm{f})$ show that $x_{L}$ decreases with $w_{i}$, and Figures $3(\mathrm{~g})$ and $3(\mathrm{~h})$ reveal that $x_{L}$ increases with $w_{j}$. Consequently, the manager leaves the employment earlier if her salary outside the industry $\left(w_{o}\right)$ or her salary after reentering the industry $\left(w_{j}\right)$ increase, and leaves her employment later if her salary while working for firm $i\left(w_{i}\right)$ increases. Notice that, the positive relation between $w_{o}$ and $x_{L}$ is because a higher $w_{o}$ means a lower opportunity cost for the manager if she leaves firm $i$, the negative relation between $x_{L}$ and $w_{i}$ is because a higher $w_{i}$ means a higher opportunity cost for the manager if she leaves firm $i$, and the positive relation between $w_{j}$ and $x_{L}$ is because a higher $w_{j}$ means that the manager will earn a higher salary if she leaves firm $i$ and reenters the industry after the termination of the embargo period. Finally, from Figures 3(i) and 3(j) we conclude that $x_{L}$ increases with $\theta$, which means that the manager leaves the employment sooner if she is able to carry more value to the competitor.

Suppose now that the manager wants to leave firm $i$ today, being $x$ the current profit value. It is possible to determine a myriad of embargo periods $(T)$ vs. severance payment $(C)$ pair values which make optimal for the manager to leave firm $i$ now $\left(x=x_{L}\right){ }^{12}$ Figure 4 shows iso-threshold lines

\footnotetext{
${ }^{12}$ Some exogenous restrictions may exist for the duration of the covenant. In fact, different countries or jurisdictions may define time-limits for the embargo period. However, we do not not discuss the "legal" maximum duration of the covenants. On the contrary, we
} 


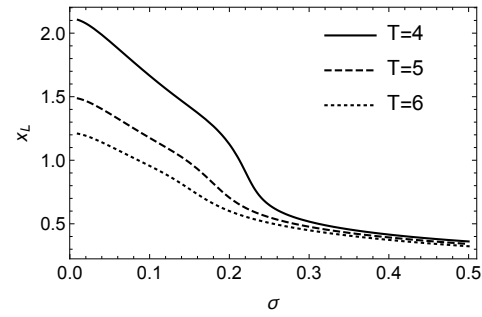

(a)

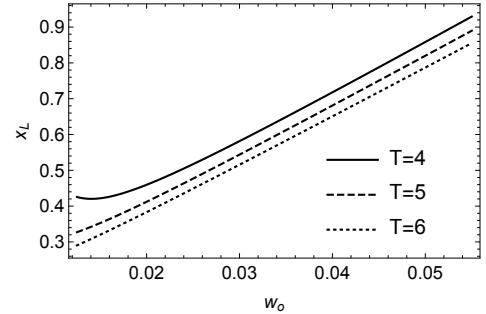

(c)

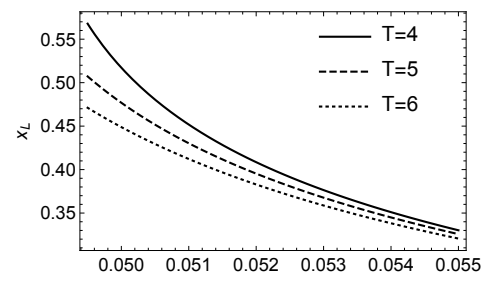

(e)

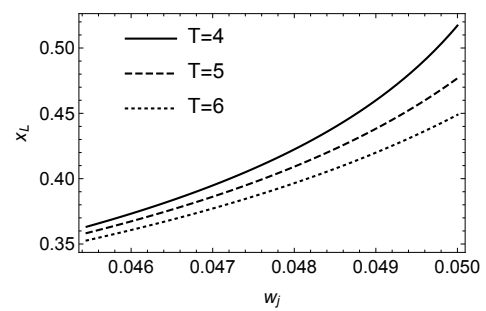

(g)

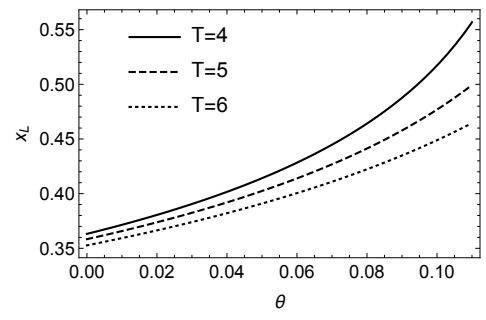

(i)

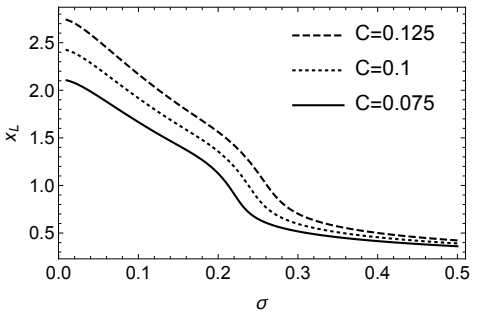

(b)

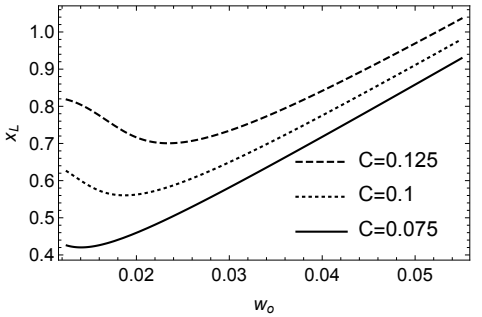

(d)

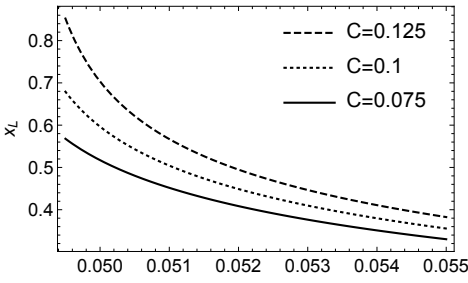

(f)

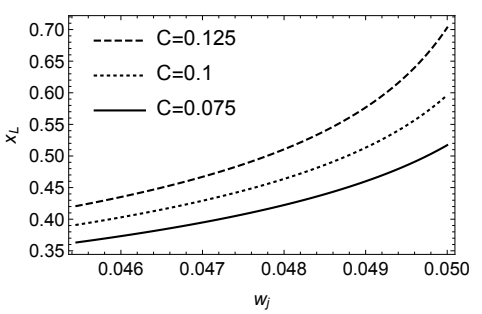

(h)

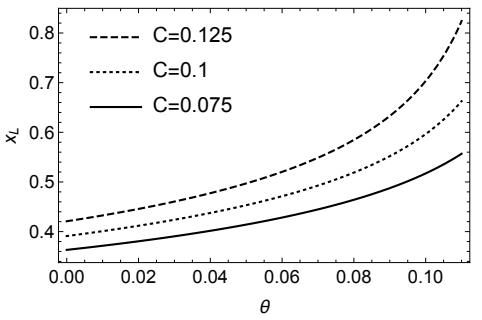

(j)

$\sigma=0.3, r=0.05, \alpha=0.01, w_{o}=0.025, w_{i}=0.05, w_{j}=0.05, \theta=0.1$.

Figure 3: A sensitivity analysis for the effect of our model parameters on the optimal threshold to leave firm $i\left(x_{L}\right)$, for a non-compete covenant (NCC). 
for different model parameters and $T$ vs. $C$ pair values. Points on the isothreshold lines represent different scenarios of $T$ vs. $C$ pair values for which it is optimal for the manager to leave firm $i$. Our findings show that $C$ increases with $T$ in all the sensitivity analyses. This is because the manager's opportunity cost, if she leaves firm $i$, increases with $T$.

More specifically, Figures 4(a) and 4(b) show that $C$ increases with both $x$ and $\sigma$. The positive relation between $x$ and $C$ is because a higher $x$ means a higher opportunity cost for the manager, if she leaves firm $i$. The positive relation between $\sigma$ and $C$ means that the manager claims a higher severance payment if the uncertainty increases, which suggests that the severance payment is significantly affected by the risk level of the industry. Figure 4(c) shows that $C$ decreases slightly with $w_{o}$ for long embargo periods, whereas the opposite occurs for short periods. Finally, Figure 4(d) shows that $C$ increases with $w_{i}$, and Figures $4(\mathrm{e})$ and $4(\mathrm{f})$ reveal that $C$ decreases with both $w_{j}$ and $\theta$, being these results in line with what is expected. In fact, a higher salary paid by $j$ and a higher value carried by the manager both promote her departure. Therefore, firm $i$ can pay less $C$ for the same departure timing.

\section{Early Reentry and Litigation}

In this section we study the scenario where the manager violates the covenant (reentering the industry before $T$ ). When the manager obeys the covenant, she reenters the industry at $t_{R}$, according to Equation (6). However, the market conditions can improve significantly while the manager is working outside the industry so as $x_{R}$ is reached before $T$ and she may consider to reenter the industry before $T$. Obviously, the manager is aware that if she does so the case can end up in court and she might be force to reimburse the firm for the value loss. Cases of litigation involving NCC are very frequent, particularly in the US. Below we analyze the above scenario from the point of view of the firm and the manager.

\subsection{The Firm}

Let us assume that the manager is in the embargo period. At any time $t<T$, firm $i$ holds a short position in the manager's FSO, whose value is

keep it open for discussion between the parties, and our model return the corresponding optimal severance payment for any given embargo period and firm profit level. 


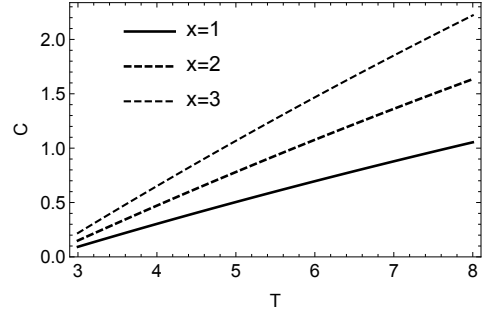

(a)

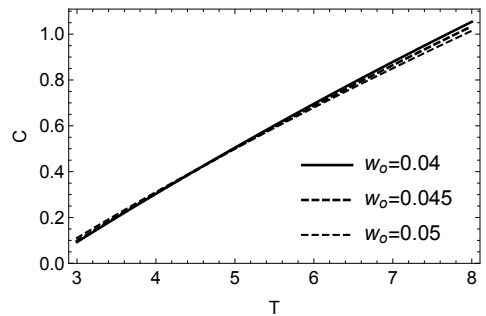

(c)

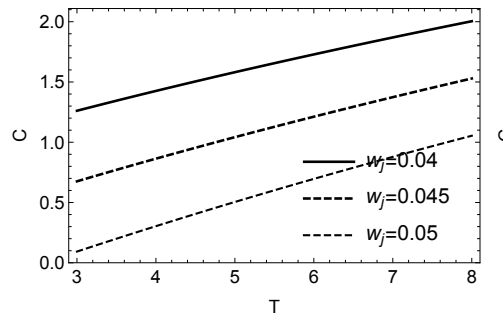

(e)

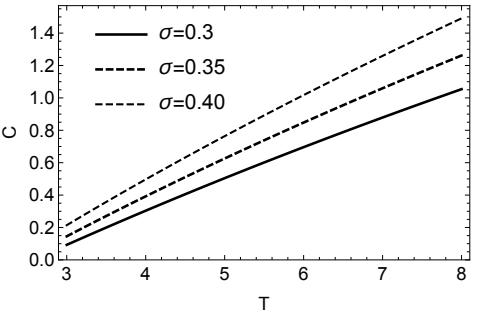

(b)

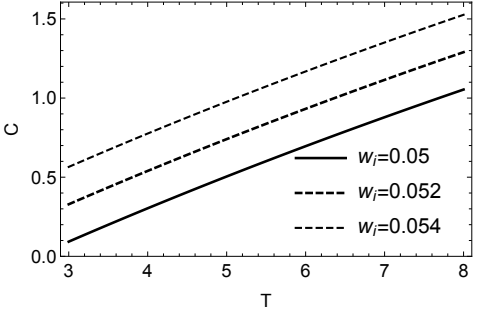

(d)

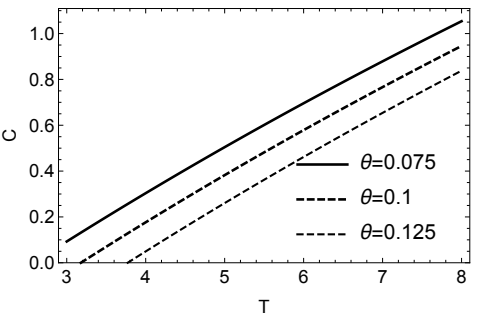

(f)

$x_{L}=x=2, \sigma=0.3, r=0.05, \alpha=0.01, w_{o}=0.025, w_{i}=0.05, w_{j}=0.05, \theta=0.1$.

Figure 4: A sensitivity analysis for the effect of our model parameters on the optimal severance payment $(C)$ versus embargo period $(T)$ pair values, for a non-compete covenant (NCC). 
given by:

$$
\begin{aligned}
H_{i}^{R}(x, t, T)= & -\theta\left(1-w_{i}\right) e^{-(r-\alpha)(T-t)} \frac{x}{r-\alpha} N\left(d_{1}(x, T-t)\right) \\
& -\theta\left(1-w_{i}\right) \frac{x_{R}}{r-\alpha}\left(\frac{x}{x_{R}}\right)^{\beta_{1}} N\left(-d_{3}(x, T-t)\right)
\end{aligned}
$$

In the right-hand side of Equation (19), the first term represents the value loss for firm $i$ if $x_{R}$ is reached before or at $T$, and the second term captures the value loss if $x_{R}$ has not yet been reached when $T$ arrives (note that the manager only exercises the FSO at $T$ if $x_{R}$ has been reached). Notice that when the manager reenters the industry working for firm $j$, the value loss of firm $i$ is partially absorbed by its new manager $\left(\theta\left(1-w_{i}\right)\right)$.

Let us assume that the manager reenters the industry before $T$, for $x \geqslant$ $x_{R}$, violating the covenant. This action leads to the following loss in value for firm $i$ :

$$
H_{i}^{N R}(x)=-\theta\left(1-w_{i}\right) \frac{x}{r-\alpha}
$$

If at the early reentry time $x \geqslant x_{R}$, one can easily show that $H_{i}^{N R}(x)>$ $H_{i}^{R}(x, t, T)$ and the firm $i$ 's value loss is given by:

$$
W_{i}(x, t, T)=H_{i}^{N R}(x)-H_{i}^{R}(x, t, T)<0, \quad \forall x>x_{R}
$$

\subsection{The Manager}

We now analyze the scenario described above but from the manager's perspective. Once again, let us assume that the manager does not obey the covenant and reenters the industry before $T$. While working outside the industry, she holds a long position in the FSO whose value is given by: ${ }^{13}$

$$
\begin{aligned}
H_{m}^{R}(x, t, T)= & F(x, T-t) \\
= & w_{j}(1+\theta) \frac{x}{r-\alpha} e^{-(r-\alpha)(T-t)} N\left(d_{1}(x, T-t)\right) \\
& -\frac{w_{o}}{r} e^{-r(T-t)} N\left(d_{2}(x, T-t)\right) \\
& +\left(w_{j}(1+\theta) \frac{x_{R}}{r-\alpha}-\frac{w_{o}}{r}\right)\left(\frac{x}{x_{R}}\right)^{\beta_{1}} N\left(-d_{3}(x, T-t)(22)\right.
\end{aligned}
$$

\footnotetext{
${ }^{13}$ See Equation (11).
} 
If the manager reenters the industry during the embargo period, her wealth is:

$$
H_{m}^{N R}(x)=w_{j}(1+\theta) \frac{x}{r-\alpha}-\frac{w_{o}}{r}
$$

and so the manager's net wealth gain is given by:

$$
W_{m}(x, t, T)=H_{m}^{N R}(x)-H_{m}^{R}(x, t, T)>0, \quad \forall x>x_{R}
$$

\subsection{Litigation}

Let us assume that the firm opts for litigation because the manager reenters the industry before $T$. As mentioned earlier, a typical litigation case involving a NCC is well illustrated by that which involved Microsoft, Google and Kai-Fu Lee. Our model provides some guidance for courts' decisions. One view could be that the reimbursement due to the firm should correspond to the illegal gains of the manager. Another view could be that the reimbursement should compensate the firm for the value loss caused by the manger's action. Therefore, the court's decision on the reimbursement amount $(Z)$ should be bounded according to $Z_{m}=W_{m}(x, t, T) \leqslant Z \leqslant Z_{i}=\left|W_{i}(x, t, T)\right|$. If courts' practice is to set $Z=Z_{m}$, the manager would be indifferent between obeying and violation the non-compete covenant, because the net effect of such behavior is nil. Hence, this practice would not prevent the violation of NCC. On the other hand, any reimbursement higher than $Z_{m}$ leads to a net loss for the manager, and the likelihood of this outcome should be pondered by the manager while deciding whether to violate the NCC or not. Naturally, the likelihood of a reimbursement lower than $Z_{m}$ encourages the manager to violate the covenant. ${ }^{14}$

\subsection{Results}

In this section we present our results and a sensitivity analysis. Figure 5 shows the effect of our model parameters on $Z_{i}$ and $Z_{m}$, for a given set of $t$ values, where $t$ represents the time at which the manager reenters the

\footnotetext{
${ }^{14} \mathrm{~A}$ more thorough analysis could also consider the direct litigation costs (i.e., court, lawyers/legal advisers fees) as well as the indirect costs such as those related to the loss of the managers' focus on the core business due to the litigation case, and the firm's conjecture about the probability of winning the case in court, but our main findings would still hold.
} 
industry. We find that for all the sensitivity analysis, $Z_{i}$ and $Z_{m}$ decrease with $t$, which is in line with what we would expect since the closer to the end of the embargo period is the reentry of the manager in the industry, the lower the value loss to the firm and the value gain for the manager. ${ }^{15}$

More specifically, Figure 5(a) and 5(b) show that the earlier (within the embargo period) the violation of the covenant, the higher is the value loss for firm $i$ and the value gain for the manager. Figures 5(c) and 5(d) show the effect of $\sigma$ on $Z_{i}$ and $Z_{m}$, respectively, for different values of $t$, and reveal that $Z_{i}$ increases and $Z_{m}$ decreases with $\sigma$. In addition, for low or relatively moderate values of $\sigma$, the sensitivity of $Z_{i}$ and $Z_{m}$ to changes in $\sigma$ is very low, but as $\sigma$ increases, a region is reached beyond which $Z_{i}$ and $Z_{m}$ both become very sensitive to $\sigma$. This means that firms from high risk industries face a much higher value loss if there is a violation of the covenant, thus they are entitled to a significantly higher reimbursement, whereas managers working in high risk industries have a much smaller value gain if they violate the covenant. This is a very important finding because it shows that the reimbursement amount is significantly affected by the risk level of the industry. ${ }^{16}$

Figure 5(e) and 5(f) show the effect of $w_{o}$ on $Z_{i}$ and $Z_{m}$, respectively, for different values of $t$, and reveal that $Z_{i}$ increases and $Z_{m}$ decreases with $w_{o}$. Thus, the higher the manager's salary outside the industry, the higher is the reimbursement if there is a violation of the covenant. Figure $5(\mathrm{~g})$ and $5(\mathrm{~h})$ show the effect of $w_{j}$ on $Z_{i}$ and $Z_{m}$, respectively, for different values of $t$, and reveal that $Z_{i}$ decreases and $Z_{m}$ increases with $w_{j}$. The intuition for the negative relation between $Z_{i}$ and $w_{j}$ is that as $w_{j}$ increases the likelihood that the manager reenters the industry at the end of the embargo period increases which, on one hand, enhances the value loss for the firm but, on the other hand, makes the loss caused by the violation of the covenant relatively smaller. The positive relation between $w_{j}$ and $Z_{m}$ is in line with what we would expect because the higher the manager's salary at firm $j$ the more

\footnotetext{
${ }^{15}$ Notice that in our sensitivity analysis we set $T=4$ as a base parameter, thus, in Figure $5, t=0.5, t=1$ and $t=1.5$ represent points in time where we are $3.5,3$ and 2.5 years from the end of the embargo period, respectively.

${ }^{16}$ Note that the manager reenters the industry at $t<T$ only if $x(t)>x_{R}$, but the higher the market profit uncertainty the more likely is that her decision to violate the covenant is non-optimal in the near future (for instance at $T$ ) which reduces the manager's gain from the violation of the covenant.
} 
advantageous is for the manager the violation of the covenant. Figure 5(i) and $5(\mathrm{j})$ show the effect of $\theta$ on $Z_{i}$ and $Z_{m}$, respectively, for different values of $t$, and reveal that $Z_{i}$ and $Z_{m}$ both increase with $\theta$, which is according to what we would expect.

\section{Garden Leave}

The use of Garden Leaves (GL) in employment agreements is also popular. The GL has a similar restriction regarding working for a competitor as the NCC, and may even prevent a manager from working at all, but during the embargo period, the manager is paid a given compensation package by the ex-employer.

We may argue that GL agreements can be more effective in those countries or jurisdictions where labor legislation has a clear distinction between employment-term and post-term restrictions (such as in Austria, Bulgaria, Argentina, or California, among others), accepting those restrictions only during the employment-term. Under this context, GL may allow to overcome the post-employment restrictive covenant enforceability in these countries, converting the post-term restriction into an employment-period one.

However, even in jurisdictions where the distinction between employmentterm and post-term restrictions does not apply, courts and policymakers tend to see more favorably GL than NCC. Also firms may prefer GL agreements since courts are more likely to enforce them than the covenants not to compete (Perri, 2010). In this section, we extend our model above to the GL agreements.

Let us assume that a manager works for firm $i$ and agrees with a GL which forbids her from working for a competitor (firm $j$ ) during an embargo period $(T)$, if she leaves the employment. Following similar arguments as for the NCC, the value of the option and the optimal threshold for the manager to leave firm $i\left(x_{G}\right)$ are determined using the following value-matching and smooth-pasting:

$$
\begin{aligned}
D_{2} x_{G}^{\beta_{2}}= & \frac{g_{0}}{r}\left(1-e^{-r T}\right)+g_{1} \frac{x_{G}}{r-\alpha}\left(1-e^{-(r-\alpha) T}\right)+F\left(x_{G}, T\right) \\
& +\frac{w_{o}}{r} e^{-r T}-w_{i} \frac{x_{G}}{r-\alpha} \\
\beta_{2} D_{2} x_{G}^{\beta_{2}-1}= & g_{1} \frac{1}{r-\alpha}\left(1-e^{-(r-\alpha) T}\right)+F_{x}\left(x_{G}, T\right)-w_{i} \frac{1}{r-\alpha}
\end{aligned}
$$




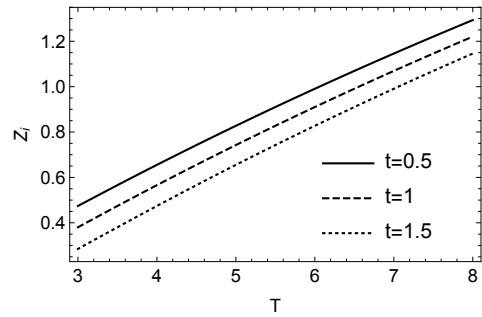

(a)

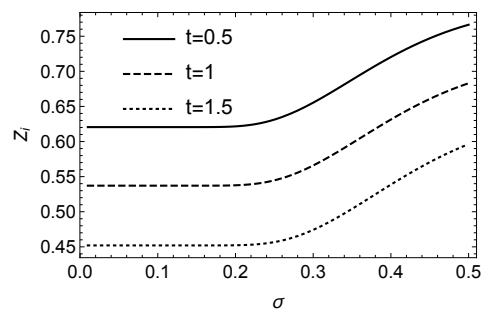

(c)

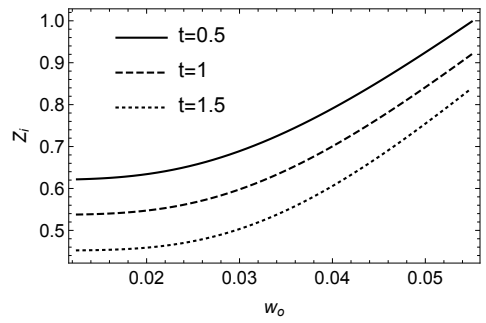

(e)

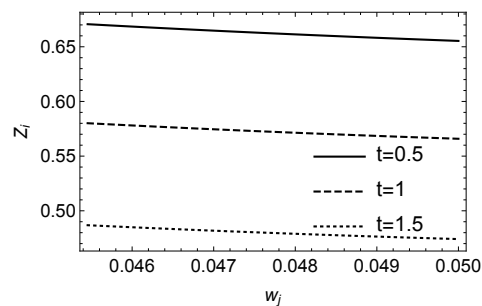

(g)

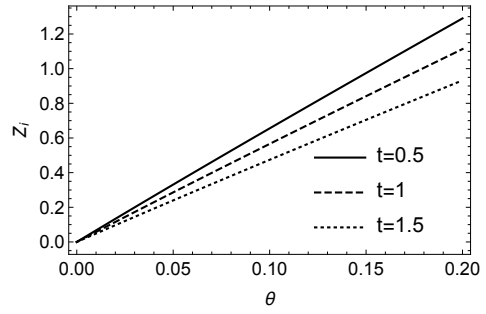

(i)

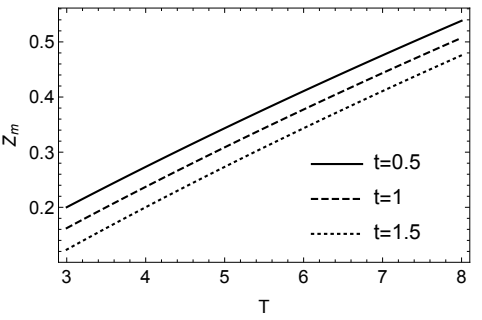

(b)

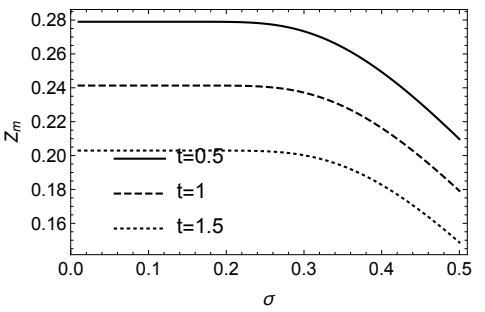

(d)

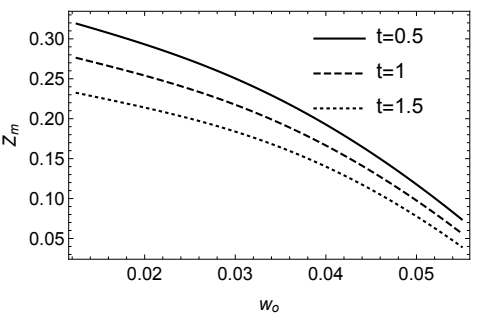

(f)

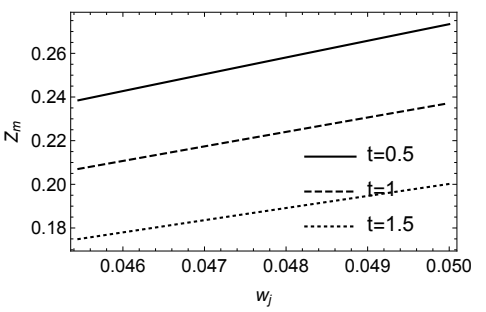

(h)

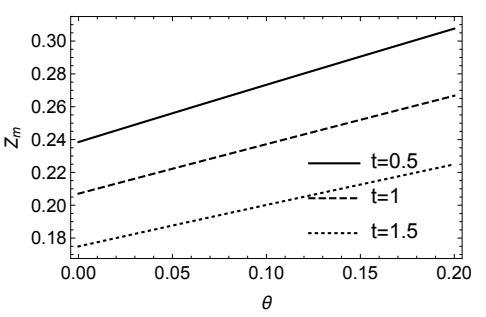

(j)

$x=2, T=4, \sigma=0.3, r=0.05, \alpha=0.01, w_{o}=0.025, w_{i}=0.05, w_{j}=0.05, \theta=0.1$.

Figure 5: A sensitivity analysis for the effect of our model parameters on the value loss of the firm $i\left(Z_{i}\right)$ and the value gain of the manager $\left(Z_{m}\right)$, when the manager is tied to a non-compete covenant (NCC) and there is a violation of the embargo period of the contract. 
The left-hand side of Equation (25) represents the value of the option to leave firm $i$ (a put option). This option is exercised as soon as its value equals that represented by the terms in the right-hand side, where, the first term represents the manager's salaries outside the industry over the embargo period (paid by firm $i$ ), the second term is the value of the FSO, the third term is the value of the manager's salary outside the industry, which exists only if at $T$ it is not yet optimal for the manager to reenter the industry, ${ }^{17}$ and the fourth is the opportunity cost for the manager if she leaves the employment. We assume that the manager's salary during the garden leave has a fixed and a variable component, being her salary at any given point in time given by $g_{0}+g_{1} x$ (with $g_{1}<w_{i}$ ). This is reasonable assumption because over the GL period the manager's salary tends to be less dependent on the firm performance.

The value of the option to leave firm $i$ is given by:

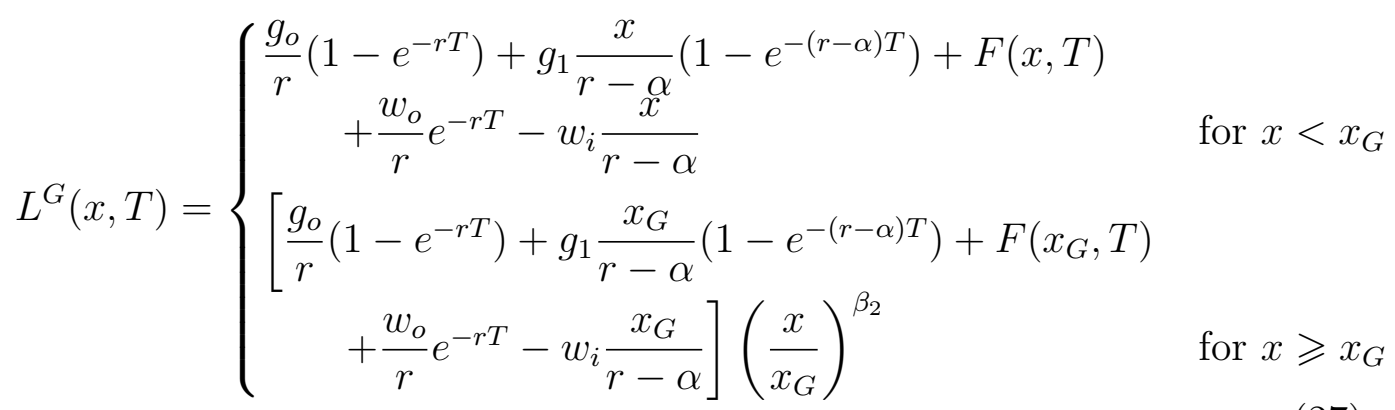

being the manager's threshold to leave firm $i\left(x_{G}\right)$ determined numerically using Equation (28):

$$
\begin{aligned}
\beta_{2}\left(\frac{g_{o}}{r}\left(1-e^{-r T}\right)+g_{1}\right. & \left.\frac{x_{G}}{r-\alpha}\left(1-e^{-(r-\alpha) T}\right)+F\left(x_{G}, T\right)+\frac{w_{o}}{r} e^{-r T}-w_{i} \frac{x_{G}}{r-\alpha}\right) \\
& -g_{1} \frac{x_{G}}{r-\alpha}\left(1-e^{-(r-\alpha) T}\right)-F_{x}\left(x_{G}, T\right) x_{G}+w_{i} \frac{x_{G}}{r-\alpha}=0
\end{aligned}
$$

\subsection{Results}

In this section we present our results for the GL and provide a comparative analysis between the GL and the NCC. Specifically, Figure 6 shows the effect

\footnotetext{
${ }^{17}$ Note that the salary outside the industry $\left(w_{o}\right)$ exists from $T$ until the optimal to reentry time if, at $T$, it is not yet optimal for the manager to reenter the industry. This aspect is taken into account in our modeling setting by considering $\frac{w_{o}}{r} e^{-r T}$ also in the expression that represents the value of FSO, so as these two terms cancel out.
} 
of our model parameters on $x_{G}$, for different values of $T$, and Figure 7 shows a comparative analysis between the NCC and the GL, regarding the effect of our model parameters on the manager's thresholds to leave $\left(x_{G}\right)$ firm $i$. Our results show that $x_{G}$ decreases with $T$ for $g_{0}, g_{1}$ and $w_{o}$, for low uncertainty and $w_{i}$, and for high $w_{j}$ and $\theta$. Thus, the manager leaves her employment later as $T$ increases in these cases.

In addition, Figures 6(a) and 6(b) show that $x_{G}$ decreases with $\sigma$ and increases with $g_{0}$, respectively. However, whilst the sensitivity of $x_{G}$ to changes in $g_{0}$ is more or less constant over $g_{0}$, the sensitivity of $x_{G}$ to changes in $\sigma$ is higher for lower values of $\sigma$. Figures $6(\mathrm{c})$ and $6(\mathrm{~d})$ reveal that $x_{G}$ increases with both $g_{1}$ and $w_{o}$. From Figures $6(\mathrm{e})$ and $6(\mathrm{f})$ we conclude that $x_{G}$ decreases with $w_{i}$ and increases with $w_{j}$, and Figure $6(\mathrm{~g})$ shows that $x_{G}$ increases with $\theta$. These results are in line with what we would expect.

Figure $7(\mathrm{a})$ shows that $x_{L}$ and $x_{G}$ both decrease with $\sigma$. Yet, for low or relatively moderate values of $\sigma$, the manager leaves the employment later if tied to a NCC. This finding is important because it suggests that if the intention of the $\mathrm{NCC}$ or the GL is to deter a manager from leaving the employment, the risk level of the industry plays an important role in the selection of the optimal contract.

Figure 7(b) shows that for both contracts the manager leaves later the employment as $T$ increases. We note however that, for long embargo periods the manager leaves the employment later when tied with NCC and the opposite holds for short embargo periods.

These results are of some significance and may justify both the popularity of the NCC, as compared to the GL, and why the GL contract is usually seen more favorably by courts. As noted in the introduction section, courts tend to see long embargo periods as being economic and socially unacceptable. It would be interesting to collect data on the length of the embargo periods of the NCC and the GL in order to examine whether there are significant differences between these two contracts. Our theoretical findings suggest that there might be.

Figures $7(\mathrm{c})$ show that both $x_{L}$ and $x_{G}$ increase with $w_{o}$, being the GL more effective in preventing the leaving of the manager, except for low values of $w_{o}$. Figure $7(\mathrm{~d})$ reveals that both $x_{L}$ and $x_{G}$ decrease with $w_{i}$. Nevertheless, for relatively low values of $w_{i}$, the NCC is more effective than the GL in preventing the leaving of the manager but, as $w_{i}$ increases, a point is reached beyond which the GL is more effective in preventing the leaving of the manager. This finding is also of some relevance because it shows that 


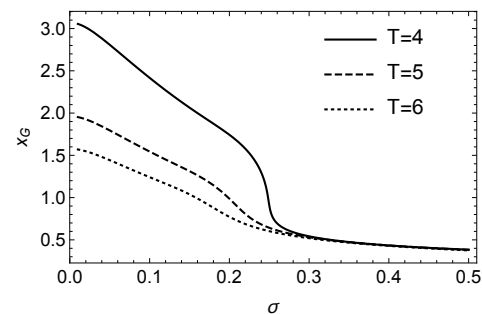

(a)

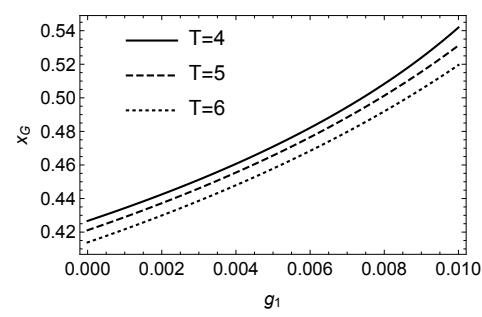

(c)

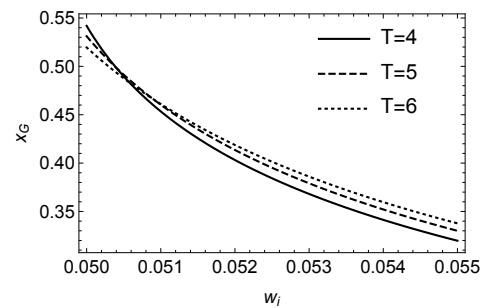

(e)

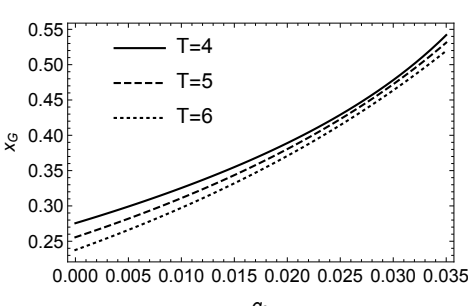

(b)

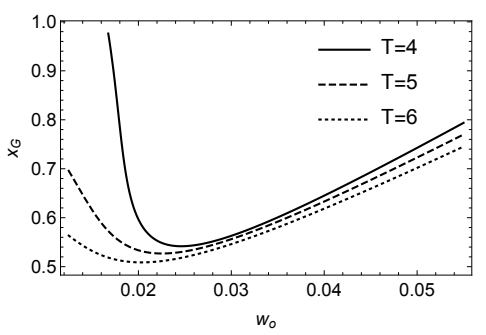

(d)

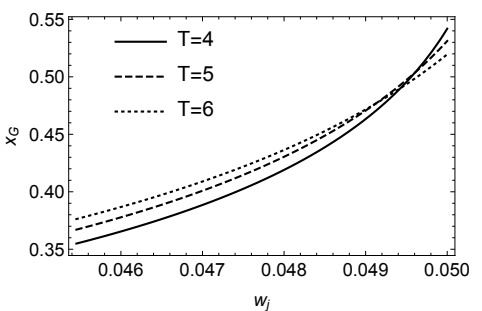

(f)

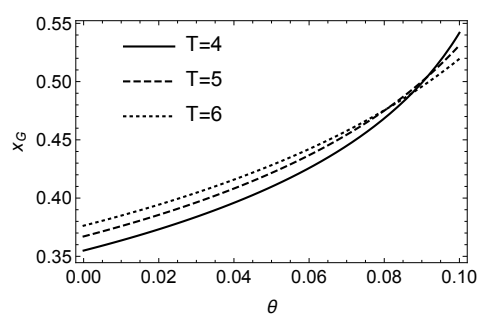

(g)

$\sigma=0.3, r=0.05, \alpha=0.01, w_{o}=0.025, w_{i}=0.05, w_{j}=0.05, \theta=0.1, g_{0}=0.03$, $g_{1}=0.01$.

Figure 6: A sensitivity analysis for the effect of our model parameters on the optimal threshold to leave firm $i\left(x_{G}\right)$ if the manager is tied to a garden leave (GL). 
the manager's salary before the termination of the employment may play a role in the selection of the contract. Indeed, our results show that the GL is a more effective contract when the manger's salary is relatively high.

Finally, Figure 7(e) and 7(f) show that both $x_{L}$ and $x_{G}$ increase with $w_{j}$ and $\theta$, and the NCC is more effective than the GL for high salaries in firm $j$ and for a high value transfer.

\section{Wealth effects}

In the model setting of the previous sections, the use of a NCC or a GL in an employment contract has no impact on the overall industry profits, i.e. these depend only on the fluctuations over time of the exogenous variable $(x)$. Nevertheless, the terms of the NCC and the GL contracts can have a significant and asymmetric wealth effect on the industry players, i.e. the two firms $(i$ and $j$ ) and the manager. Thus, we provide in this section a wealth effect analysis.

The manager of firm $i$, under a NCC or a GL, loses the increment in salary from moving immediately to firm $j$ and gains the option to leave $L(x, T)$ for a NCC (Equation (17)), or $L^{G}(x, T)$ for a GL (Equation (27)). The wealth effect for the NCC and the GL are, respectively, given by:

$$
\begin{aligned}
\Pi(x, T) & =L(x, T)-\left(w_{j}(1+\theta)-w_{i}\right) \frac{x}{r-\alpha} \\
\Pi_{m}^{G}(x, T) & =L^{G}(x, T)-\left(w_{j}(1+\theta)-w_{i}\right) \frac{x}{r-\alpha}
\end{aligned}
$$

When using a NCC, the wealth effect for firm $i$ is the following:

$$
\begin{aligned}
\Pi_{i}(x, T)= & \theta\left(1-w_{i}\right) \frac{x}{r-\alpha}-\left[\theta\left(1-w_{i}\right) e^{-(r-\alpha) T} \frac{x_{L}}{r-\alpha} N\left(d_{1}\left(x_{L}, T\right)\right)\right. \\
& \left.+\theta\left(1-w_{i}\right) \frac{x_{R}}{r-\alpha}\left(\frac{x_{L}}{x_{R}}\right)^{\beta_{1}} N\left(-d_{3}\left(x_{L}, T\right)\right)+C\right]\left(\frac{x}{x_{L}}\right)^{\beta_{2}}, \quad \text { for } x \geqslant x_{L}
\end{aligned}
$$

With the NCC, the firm (i) prevents the impact of losing the manager immediately to firm $j$; (ii) holds a short position on the manager FSO to reenter the industry (obtained from Equation (19) with $t=0$ ); and (iii) also holds a short position on the option of the manager to leave the firm, upon which the severance payment is due. Hence, the NCC delays a value loss 


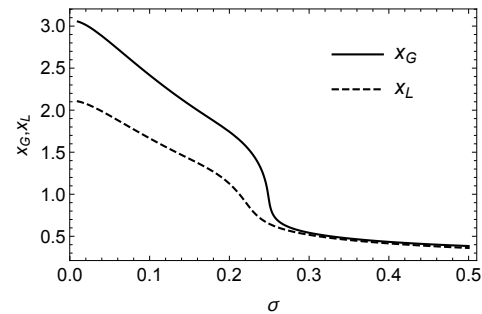

(a)

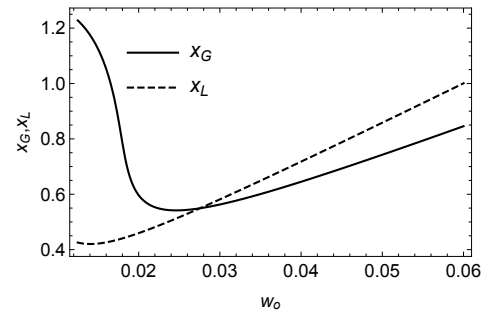

(c)

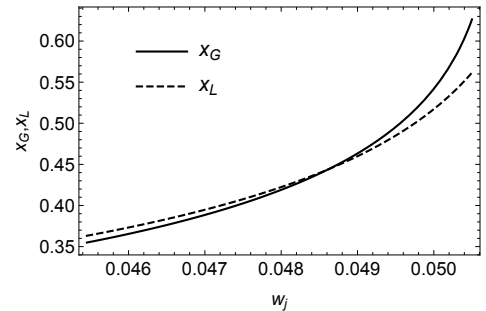

(e)

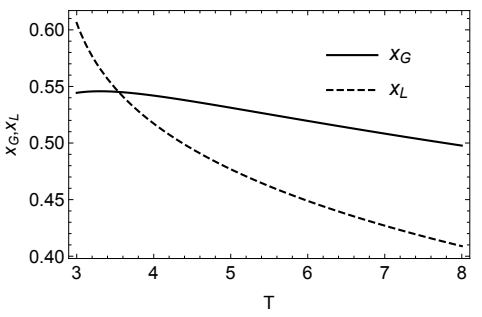

(b)

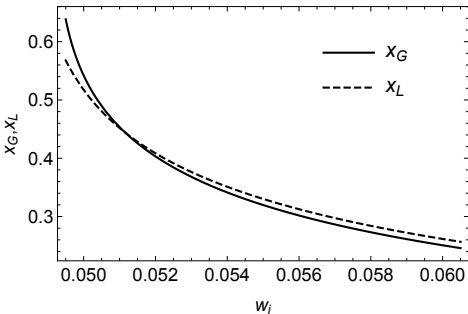

(d)

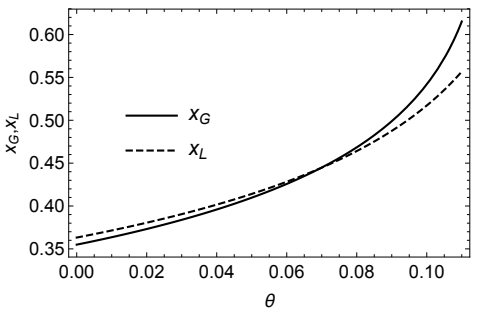

(f)

$T=4, C=0.075, \sigma=0.3, r=0.05, \alpha=0.01, w_{o}=0.025, w_{i}=0.05, w_{j}=0.05, \theta=0.1$, $g_{0}=0.03, g_{1}=0.01$.

Figure 7: A comparative sensitivity analysis between a non-compete covenant (NCC) and a garden leave (GL), regarding the effect of our model parameters on the optimal thresholds to leave firm $i$. 
related to an immediate move of the manager to firm $j$, but this value loss protection is made at a cost: the severance payment $(C)$. We note that the last two terms of the above equation are discounted to the current level of $x$.

Similarly, the wealth effect form firm $i$ when using a GL is the following:

$$
\begin{aligned}
\Pi_{i}^{G}(x, T)= & \theta\left(1-w_{i}\right) \frac{x}{r-\alpha}-\left[\theta\left(1-w_{i}\right) e^{-(r-\alpha) T} \frac{x_{G}}{r-\alpha} N\left(d_{1}\left(x_{G}, T\right)\right)\right. \\
& +\theta\left(1-w_{i}\right) \frac{x_{R}}{r-\alpha}\left(\frac{x_{G}}{x_{R}}\right)^{\beta_{1}} N\left(-d_{3}\left(x_{G}, T\right)\right) \\
& \left.+w_{i} \frac{x_{G}}{r-\alpha}\left(1-e^{-(r-\alpha) T}\right)\right]\left(\frac{x}{x_{G}}\right)^{\beta_{2}}, \quad \text { for } x \geqslant x_{G}
\end{aligned}
$$

Notice that the difference between the GL and the NCC regarding the wealth effect lies only in the final term, where the severance payment associated with the NCC is replaced by the manager's salary over the GL period.

Contrary to what happens to firm $i$, firm $j$ has a positive payoff when the manager exercises the option to reenter the industry:

$$
\begin{aligned}
\Pi_{j}(x, T)= & -\theta\left(1-w_{j}\right) \frac{x}{r-\alpha}+\left[\theta\left(1-w_{j}\right) e^{-(r-\alpha) T} \frac{x_{L}}{r-\alpha} N\left(d_{1}\left(x_{L}, T\right)\right)\right. \\
& \left.+\theta\left(1-w_{j}\right) \frac{x_{R}}{r-\alpha}\left(\frac{x_{L}}{x_{R}}\right)^{\beta_{1}} N\left(-d_{3}\left(x_{L}, T\right)\right)\right]\left(\frac{x}{x_{L}}\right)^{\beta_{2}}, \quad \text { for } x \geqslant x_{L}
\end{aligned}
$$

$$
\begin{aligned}
\Pi_{j}^{G}(x, T)= & -\theta\left(1-w_{j}\right) \frac{x}{r-\alpha}+\left[\theta\left(1-w_{j}\right) e^{-(r-\alpha) T} \frac{x_{G}}{r-\alpha} N\left(d_{1}\left(x_{G}, T\right)\right)\right. \\
& \left.+\theta\left(1-w_{j}\right) \frac{x_{R}}{r-\alpha}\left(\frac{x_{G}}{x_{R}}\right)^{\beta_{1}} N\left(-d_{3}\left(x_{G}, T\right)\right)\right]\left(\frac{x}{x_{G}}\right)^{\beta_{2}}, \quad \text { for } x \geqslant x_{G}
\end{aligned}
$$

The NCC or the GL delays a value gain for firm $j$ and the wealth effects of these two contracts are the same if $x_{L}=x_{G}$. Notice that, the difference between the current industry profit level $(x)$ and the manager's thresholds to leave $\left(x_{L}\right.$ and $\left.x_{G}\right)$ is a key factor for the analysis of the wealth effects. Specifically, when these get closer, it favors the wealth of firm $j$ and the wealth of the manager, and damages the wealth of firm $i$. We analyze the 
wealth effects of three agents: the manager and firms $i$ and $j$. The remaining wealth effect is borne by the managers of the other firms operating in the market. Below, we provide a wealth effect sensitivity analysis for the effect of $T, \sigma$ and $\theta$.

From our results (refer to Figures 8, 9 and 10), the big picture that is worth mentioning is that the non-compete agreements (NCC and GL) produce negative wealth effects, both for the employee and the competing firm (firm $j$ ). ${ }^{18}$ Moreover, the aggregate wealth impact reveals to be negative.

Our results seem to support the broad negative view that courts and policymakers have on NCC and GL (Callahan, 1985; Den Hertog, 2003). However, contrary to what seems to be a higher tolerance about GL, when compared to NCC, revealed by courts and policymakers (Klein and Pappas, 2009) our results seem to show that, in aggregate terms, NCC are less harmful than GL. However, if the courts decisions concern mainly employees' position, we see that, depending on the embargo period and uncertainty, one instrument can be less negative than the other.

An interesting question refers to the motivation for an employee to accept an agreement that reveals to be painful for her. The justification may rely on some of the motives reported by Starr et al. (2017), not incorporated in our setting, namely that a negotiation was not possible, there was a fear of being fired, to avoid tension, the belief that the employer would not sue or the court would not enforce.

\section{Conclusion}

We develop a dynamic model which assesses non-compete covenants (NCC) and garden leaves (GL) in employment agreements. We examine the effect of these contracts on the manager's behavior regarding the termination of the employment and the violation of the NCC, and the behavior of both the firm and the manager concerning the negotiation of these agreements. It is the first theoretical model that evaluates the firm-manager competing interests comparing NCC to GL under uncertainty.

Our findings can have significant future implications in the negotiation of NCC and GL, as well as on the evaluation of the enforceability of these

\footnotetext{
${ }^{18}$ The only exception is for low values of $\theta$. In our analysis we ignore this case because, naturally, if the manager carries low value when moving to $j$, firm $i$ will be less interested in promoting a non-competing agreement.
} 


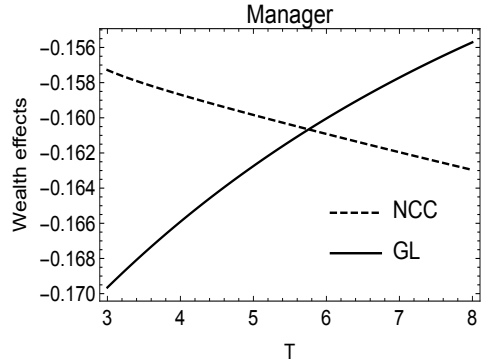

(a)

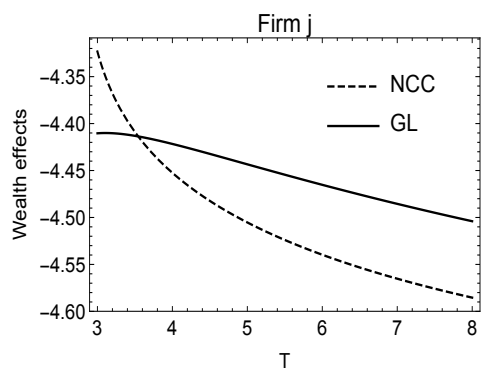

(c)

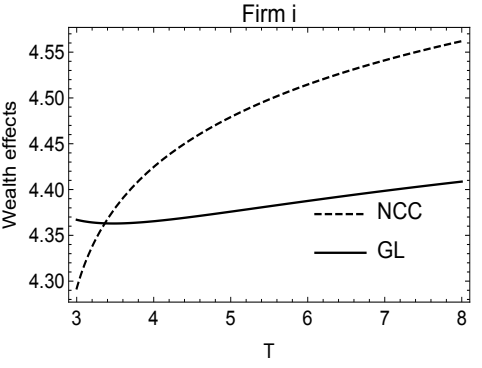

(b)

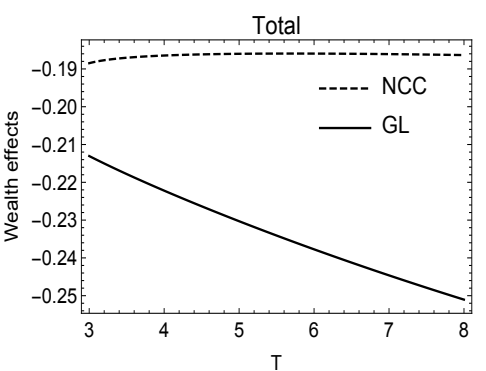

(d)

$x=2, T=4, \sigma=0.3, r=0.05, \alpha=0.01, w_{o}=0.025, w_{i}=0.05, w_{j}=0.05, \theta=0.1$, $g_{0}=0.03, g_{1}=0.01, C=0.075$.

Figure 8: A sensitivity analysis of the effect of the embargo period $(T)$ on the wealth. 


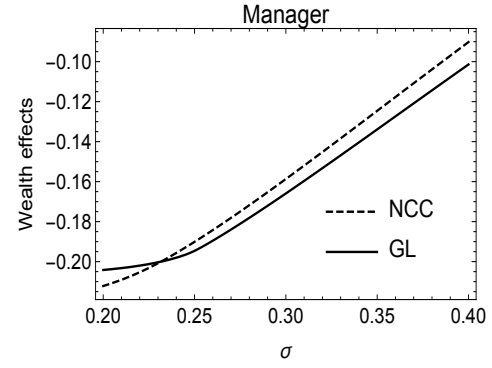

(a)

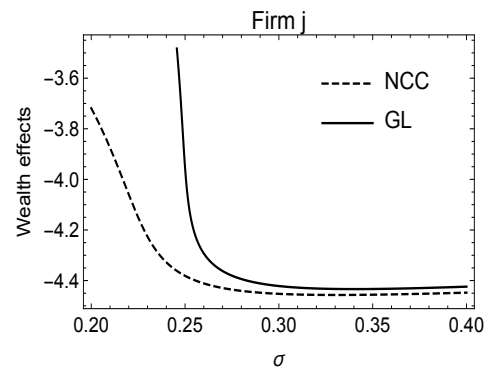

(c)

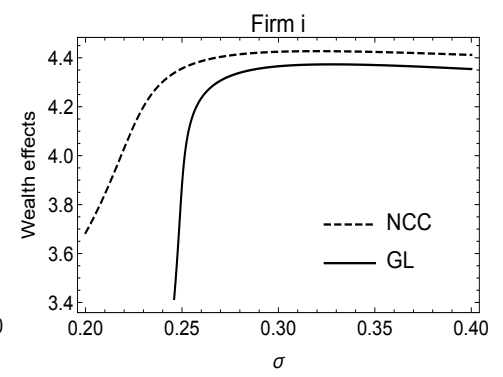

(b)

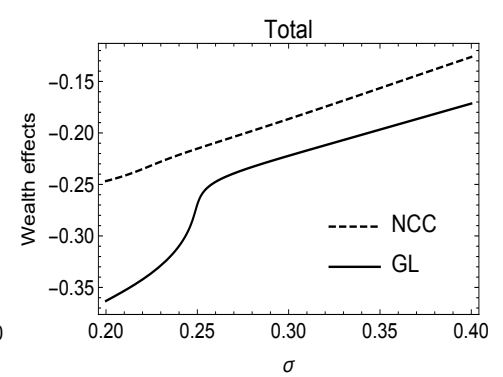

(d)

$x=2, T=4, \sigma=0.3, r=0.05, \alpha=0.01, w_{o}=0.025, w_{i}=0.05, w_{j}=0.05, \theta=0.1$, $g_{0}=0.03, g_{1}=0.01, C=0.075$.

Figure 9: A sensitivity analysis of the effect of uncertainty $(\sigma)$ on the wealth. 


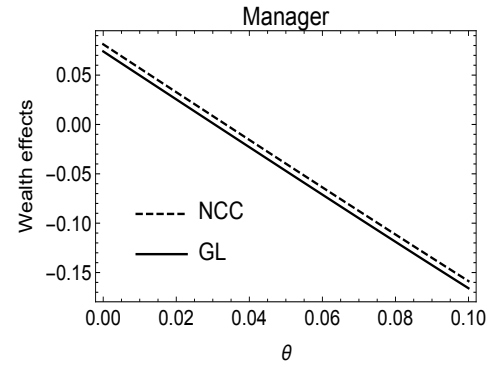

(a)

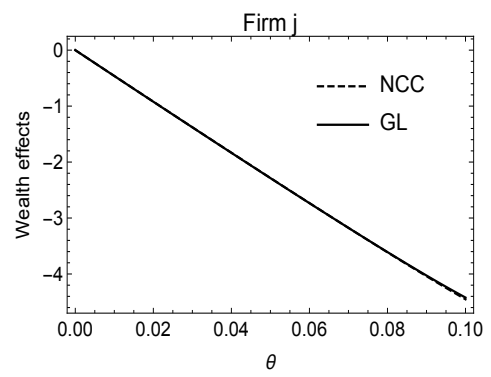

(c)

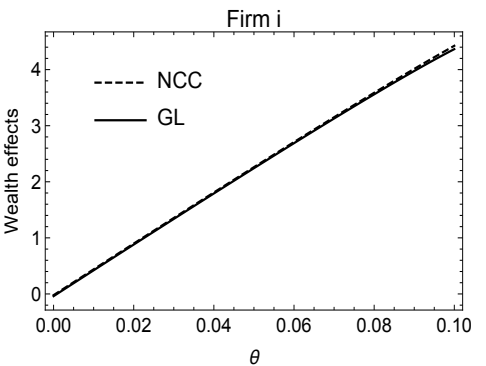

(b)

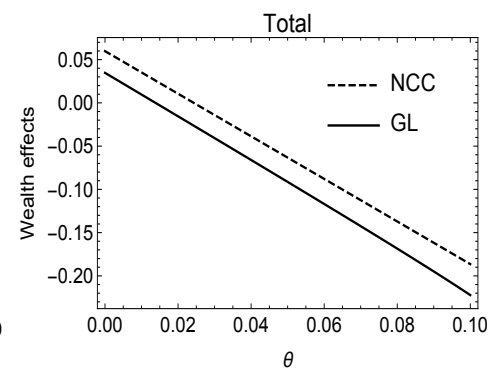

(d)

$x=2, T=4, \sigma=0.3, r=0.05, \alpha=0.01, w_{o}=0.025, w_{i}=0.05, w_{j}=0.05, \theta=0.1$, $g_{0}=0.03, g_{1}=0.01, C=0.075$.

Figure 10: A sensitivity analysis for the effect of the value loss/gain to firm $i / j(\theta)$ caused by the departure of the manager from firm $i$ to firm $j$ on the wealth. 
contracts. For the NCC, we conclude that the embargo period and the severance payment largely determine the manager's behavior regarding the termination of the employment and the timing of the manager for the (illegal) early reentry in the industry. We also find that the reimbursement amount is significantly affected by the industry uncertainty. For low or relatively moderate levels of uncertainty, it is only slightly sensitive to uncertainty changes, but as it increases beyond a certain level, the reimbursement increases significantly with uncertainty. Thus, firms operating in industries with higher risk are entitled to higher reimbursements.

Comparing NCC with GL, we conclude that, for low or relatively moderate market uncertainty, the manager leaves the employment later if tied to a NCC. This is a very important result because it provides some guidance on the selection of the optimal contract considering the market conditions and the existing laws and regulations which inhibit the use of long embargo periods. The manager also leaves later the firm if tied to a NCC when the embargo period is long, or her salary now or when working outside the industry is low, or her salary when working for the competitor or the damage that is associated with the departure of the manager to the competitor is high.

We also compare the NCC with GL using their wealth effects, showing how the competing interests of the manager and the firm are influenced by the model parameters. Our results seem to support the broad negative view that courts and policymakers have on NCC and GL. However, contrary to what seems to be a higher tolerance about GL, when compared to NCC, revealed by courts and policymaker, our results suggest that, in aggregate terms, NCC are less harmful than GL. However, if courts are mostly concerned with the manager's position, the instrument which is less harmful depends on the embargo period and uncertainty.

It would be a very valuable research to test empirically some of our main findings, if there is data available. For instance, by examining the relationship between the industry uncertainty and the popularity of the NCC and GL, or studying whether there is a significant difference between the embargo periods of the NCC and GL, or investigating whether the embargo periods of the NCC and GL are determined by the industry uncertainty. From a theoretical point of view, it would be interesting to go one step back in our modeling setting and studying this decision problem at the hiring and negotiation stages. 


\section{Appendix A. Proof of Equation 11}

For the analytical derivation of the forward start option (FSO) value, we need the discounted risk-neutral expected value, which is given by:

$$
F(x, T)=e^{-r T} E[R(x(T))]
$$

where $R(x(T))$ is the value of the option to reenter at time $T$. Note that from Equation (9) $R(x(T))$ has two regions, therefore:

$$
\begin{array}{r}
F(x, T)=e^{-r T} E\left[\left(w_{j}(1+\theta) \frac{x}{r-\alpha}-\frac{w_{o}}{r}\right) \mathbf{1}_{x(T) \geqslant x_{R}}\right] \\
+e^{-r T} E\left[g x(T)^{\beta_{1}} \mathbf{1}_{x(T)<x_{R}}\right]
\end{array}
$$

where $g=\left(w_{j}(1+\theta) \frac{x_{R}}{r-\alpha}-\frac{w_{o}}{r}\right)\left(\frac{1}{x_{R}}\right)^{\beta_{1}}$, and $\mathbf{1}_{\text {condition }}$ equals 1 if the condition is met, and 0 otherwise.

Following Shackleton and Wojakowski (2007), the first component in $F(x, T)$ is the difference between an asset-or-nothing call option on $w_{j}(1+\theta) \frac{x(T)}{r-\alpha}$, and a cash-or-nothing call option on $\frac{w_{o}}{r}$, with exercise price $x_{R}$, and maturity $T$ :

$$
\begin{array}{r}
e^{-r T} E\left[R(x(T)) \mathbf{1}_{x(T) \geqslant x_{R}}\right]=w_{j}(1+\theta) \frac{x}{r-\alpha} e^{-(r-\alpha) T} N\left(d_{1}(x, T)\right) \\
-\frac{w_{o}}{r} e^{-r T} N\left(d_{2}(x, T)\right)
\end{array}
$$

where

$$
\begin{aligned}
& d_{1}(x, T)=\frac{\ln \left(\frac{x}{x_{R}}\right)+\left(\alpha+\frac{1}{2} \sigma^{2}\right) T}{\sigma \sqrt{T}} \\
& d_{2}(x, T)=d_{1}(x, T)-\sigma \sqrt{T}
\end{aligned}
$$

From the Appendix A of Shackleton and Wojakowski (2007) we acknowledge that the second component of $F(x, T)$ is:

$$
\begin{aligned}
& e^{-r T} E\left[R(x(T)) \mathbf{1}_{x(T)<x_{R}}\right]=g x^{\beta_{1}} N\left(-d_{3}(x, T)\right) \\
& =\left(w_{j}(1+\theta) \frac{x_{R}}{r-\alpha}-\frac{w_{o}}{r}\right)\left(\frac{x}{x_{R}}\right)^{\beta_{1}} N\left(-d_{3}(x, T)\right)
\end{aligned}
$$


where

$$
\begin{aligned}
& d_{3}(x, T)=\frac{\ln \left(\frac{x}{x_{R}}\right)+\left(\alpha+\left(\beta_{1}-\frac{1}{2}\right) \sigma^{2}\right) T}{\sigma \sqrt{T}} \\
& d_{3}(x, T)=d_{1}(x, T)+\left(\beta_{1}-1\right) \sigma \sqrt{T}
\end{aligned}
$$

Shackleton and Wojakowski (2007) show that the risk-neutral expectation of a claim $x(T)^{\beta}$, for a general $\beta$, conditional on the initial value $x$ is:

$$
\begin{aligned}
& e^{-r T} E\left[x(T)^{\beta} \mathbf{1}_{x(T) \geqslant x_{R}}\right]=e^{q(\beta) T} x^{\beta} N(h(\beta)) \\
& e^{-r T} E\left[x(T)^{\beta} \mathbf{1}_{x(T)<x_{R}}\right]=e^{q(\beta) T} x^{\beta} N(-h(\beta))
\end{aligned}
$$

where

$$
\begin{aligned}
& h(\beta)=\frac{\ln \left(\frac{x}{x_{R}}\right)+\left(\alpha+\left(\beta-\frac{1}{2}\right) \sigma^{2}\right) T}{\sigma \sqrt{T}} \\
& q(\beta)=\frac{1}{2} \sigma^{2} \beta(\beta-1)+\alpha \beta-r
\end{aligned}
$$

In our notation, $d_{1}(x, T)=h(1), d_{2}(x, T)=h(0)$, and $d_{3}(x, T)=h\left(\beta_{1}\right)$. Noting that $q(1)=-(r-\alpha), q(0)=-r, q\left(\beta_{1}\right)=0$, Equations (A.3) and (A.6) are obtained.

\section{Acknowledgments}

We would like to thank the anonymous referees and the helpful advices and suggestions for improvements on the earlier versions of the paper given by Roger Adkins, Sebastian Eichfelder, Izidin El Kalak, Stefan Kupfer, Michael Kvasnicka, Gilberto Loureiro, Elmar Lukas, Tomasz Mickiewicz, Ryan Murphy, Tiago Pinheiro, Dean Paxson, Karim Sadrieh, Miguel Sousa, Radu Tunaru, Andrianos Tsekrekos, Andreas Welling and participants of the seminars at Aston Business School, Kent Business School, and Otto von Guericke University Magdeburg, and the 2016 Real Options Conference. 
Almazan, A. and Suarez, J. (2003). Entrenchment and severance pay in optimal governance structures. The Journal of Finance, 58(2):519-548.

Anenson, T. L. (2005). Litigation between competitors with mirror restrictive covenants: A formula for prosecution. Stanford Journal of Law, Business, and Finance, 10(2).

Barney, J. B., Busenitz, L., Fiet, J., and Moesel, D. (1994). The relationship between venture capitalists and managers in new firms: determinants of contractual covenants. Managerial finance, 20(1):19-30.

Bishara, N. and Orozco, D. (2012). Using the resource-based theory to determine covenant not to compete legitimacy. Indiana Law Journal, 87:9791031.

Bishara, N. and Starr, E. P. (2016). The incomplete noncompete picture.

Bite, V. (2011). Non-competition convenants in case of a business transfer. Jurisprudencija, 18(1):177-198.

Blake, H. M. (1960). Employee agreements not to compete. Harvard Law Review, 73(4):625-691.

Bryenton, G. L. (1964). Validity and enforceability of restrictive covenants not to compete. W. Res. L. Rev., 16:161-189.

Buente, A. V. (2012). Enforceability of noncompete agreements in the buckeye state: how and why Ohio courts apply the reasonableness standard to entrepreneurs. Ohio St. Entrepren. Bus. LJ, 8:73-98.

Callahan, M. B. (1985). Post-employment restraint agreements: A reassessment. The University of Chicago Law Review, 52(3):703-728.

Conti, R. (2014). Do non-competition agreements lead firms to pursue risky R\&D projects? Strategic Management Journal, 35(8):1230-1248.

Dahiya, S. and Yermack, D. (2008). You can't take it with you: Sunset provisions for equity compensation when managers retire, resign, or die. Journal of Corporate Finance, 14(5):499-511.

Den Hertog, J. (2003). Noncompetition clauses: Unreasonable or efficient? European Journal of Law and Economics, 15(2):111-127. 
Edmans, A. and Gabaix, X. (2009). Is ceo pay really inefficient? A survey of new optimal contracting theories. European Financial Management, 15(3):486-496.

Gaby Hardwicke Solicitors (2011). Imposing restrictive covenants in a business sales.

Garmaise, M. J. (2011). Ties that truly bind: Noncompetition agreements, executive compensation, and firm investment. The Journal of Law, Economics, and Organization, 27(2):376-425.

Gilson, R. J. (1999). The legal infrastructure of high technology industrial districts: Silicon Valley, Route 128, and covenants not to compete. New York University Law Review, 74(3):575-629.

Helfdt, M. (2009a). Unwritten code rules Silicon Valley hiring. New York Times, June(3).

Helfdt, M. (2009b). U.s. inquiry into hiring at high-tech companies. New York Times, June(2).

Horvitz, K. D. (2016). An unreasonable ban on reasonable competition: The legal professions protectionist stance against noncompete agreements binding in-house counsel. Duke LJ, 65:1007-1053.

Hutter, M. J. (1981). Drafting enforceable employee non-competition agreements to protect confidential business information: A lawyer's practical approach to the case law. Albany Law Review, 45:311-352.

Hyde, A. (2003). Working in Silicon Valley: Economic and legal analysis of a high-velocity labor market. ME Sharpe.

Klein, J. S. and Pappas, N. J. (2009). Garden leaveclauses in lieu of noncompetes. New York Law Journal, 241.

Kobeissi, N., Sun, X., and Wang, H. (2010). Managerial labor-market discipline and the characteristics of merger and acquisition transactions. Journal of Business Research, 63(7):721-728.

Kräkel, M. and Sliwka, D. (2009). Should you allow your employee to become your competitor? on noncompete agreements in employment contracts. International Economic Review, 50(1):117-141. 
Lavetti, K., Simon, C. J., and White, W. (2014). Buying loyalty: Theory and evidence from physicians.

Mack, C. (2015). Postemployment noncompete agreements: Why utah should depart from the majority. Utah L. Rev., page 1201.

Marx, M. (2011). The firm strikes back: non-compete agreements and the mobility of technical professionals. American Sociological Review, 76(5):695-712.

Marx, M., Singh, J., and Fleming, L. (2015). Regional disadvantage? employee non-compete agreements and brain drain. Research Policy, $44(2): 394-404$.

Perri, T. J. (2010). Garden leave vs. covenants not to compete. Review of Law \& Economics, 6(2):167-179.

Peters, F. S. and Wagner, A. F. (2014). The executive turnover risk premium. The Journal of Finance, 69(4):1529-1563.

Schwab, S. J. and Thomas, R. S. (2006). An empirical analysis of ceo employment contracts: What do top executives bargain for. Wash. \& Lee L. Rev., 63:231-270.

Shackleton, M. B. and Wojakowski, R. (2007). Finite maturity caps and floors on continuous flows. Journal of Economic Dynamics and Control, 31(12):3843-3859.

Starr, E. P., Bishara, N., and Prescott, J. (2017). Noncompetes in the US labor force. Available at SSRN: https://ssrn.com/abstract=2625714.

Tang, M., Wang, R., and Zhou, Y. (2016). Labor market mobility and expectation management: Evidence from enforceability of non-compete provisions. 